2.

Derecho político 

Revista de Derecho

de la Pontificia Universidad Católica de Valparaíso

XXX (Valparaíso, Chile, $1^{\text {er }}$ Semestre de 2008)

[pp. 185 - 219]

\title{
LA DOCTRINA DE LA SEPARACIÓN DE PODERES Y EL PODER JUDICIAL CHILENO*
}

[The Doctrine Regarding Separation of Powers and the Chilean Judicial Power]

\author{
Andrés Bordalí Salamanca** \\ Universidad Austral de Chile
}

\begin{abstract}
RESUMEN
El presente trabajo analiza las razones históricas y teóricas que fundan la doctrina de la división de poderes, con especial referencia al poder judicial y su necesidad de independencia de los poderes políticos. El estudio comprende cómo se ha entendido dicha doctrina en el Derecho chileno, analizando críticamente la concepción mayoritaria de la dogmática constitucional chilena en orden a considerar que los órganos políticos pueden ejercer la función jurisdiccional.
\end{abstract}

Palabras clave: Jurisdicción - Tribunales de justicia - Independencia judicial - Función jurisdiccional - Separación de poderes.

\section{Abstract}

This work analyses the historical and theoretical reasons that are the basis for the division of power, with special reference to the judicial power and its need to be independent from the political powers. This analysis comprises the study of how said doctrine in the Chilean law has been understood. To do this we analysed, from the critique standpoint, the majority conception of the Chilean constitutional dogma in order to consider that the political bodies can exert the jurisdictional function.

Keywords: Jurisdiction - Justice Courts - Judicial Independence - Jurisdictional Function - Separation of powers.

* Este trabajo se inscribe en el marco de una investigación más general que se está desarrollando con financiamiento del proyecto FONDECYT No 1070211 titulado: "Organización y función judicial en el sistema constitucional chileno", del que el autor de este artículo es su investigador responsable. Esta investigación ha contado con la colaboración de los profesores Daniela Accatino Scagliotti y Juan Carlos Ferrada Bórquez quienes son coinvestigadores en el referido proyecto FondeCYT.

** Doctor en Derecho; Profesor de Derecho Procesal de la Universidad Austral de Chile. Dirección postal: Campus Isla Teja s/n, Casilla 567, Valdivia, Chile. Correo electrónico: abordali@uach.cl 


\section{INTRODUCCIÓN}

Uno de los pilares fundamentales del Estado de Derecho es la división del poder estatal. Los poderes legislativo, ejecutivo y judicial, los tradicionales tres poderes, deben encontrarse separados o divididos. Esto es lo que cualquier buen ciudadano de una democracia occidental aprende desde la escuela. Dicha situación permite a ese ciudadano aceptar como legítimas las decisiones de los poderes del Estado y le hace pensar que su vida, libertad y bienes está más o menos resguardada. Hasta aquí todo reina en paz.

Sin embargo, si se interroga a ese buen ciudadano sobre dónde ubicar a poderes como el Tribunal Constitucional que puede imponer sus decisiones a los otros tres poderes del Estado, surgirá en él la duda si es que hay más de tres poderes en el Estado. ¿Cuántos son en realidad los poderes del Estado?

Luego se le podría preguntar a ese mismo ciudadano si es necesario que cada poder desarrolle sólo una función, o bien, si es posible que una función pueda ser compartida por dos o más poderes. Lo más probable es que la tranquilidad de nuestro hombre comience a decaer. ¿Pueden el legislativo o el ejecutivo resolver conflictos de relevancia jurídica de carácter temporal con efectos de cosa juzgada? Es decir, ipueden ejercer poderes distintos del judicial la función jurisdiccional? Se trata en definitiva de determinar si lo relevante es dividir el poder atribuyendo a cada órgano creado una específica función, o bien, lo que importa es que las funciones del Estado se encuentren divididas haciendo abstracción del órgano que las desarrolle. Si lo que importa es que las funciones se encuentren divididas, ¿entonces la función jurisdiccional puede ser desarrollada por órganos que no son independientes del poder político? Si ello es así, ¿cuál es el sentido entonces de la división de poderes?

Responder algunas de estas cuestiones es especialmente complejo si ese buen ciudadano vive en la República de Chile. Es que nuestra doctrina y jurisprudencia mayoritarias aceptan que tanto el legislativo como el ejecutivo ejerzan jurisdicción. Se entiende que el Senado ejerce jurisdicción al conocer de las acusaciones constitucionales; la Administración del Estado también ejerce jurisdicción al conocer del contencioso tributario, aduanero, de transportes, etc. En el caso que la Administración ejerza jurisdicción surge el cuestionamiento de cuál es la finalidad de asegurar la independencia del poder judicial si se va a permitir que la Administración ejerza jurisdicción en asuntos en los que ella es parte.

A mi entender, como intentaré justificar en la presente trabajo, para que la división de poderes tenga sentido en un Estado de Derecho, es necesario que los poderes políticos, es decir, el legislativo y el ejecutivo, no puedan 
desarrollar la función jurisdiccional. Si entendemos por esta última una función estatal que tiene por objeto aplicar en el caso concreto y con efectos irrevocables el mandato general y abstracto del legislativo o la decisión jurídica del ejecutivo, dicha función debe quedar confiada a los tribunales de justicia los que se caracterizan por ser orgánicamente independientes del poder legislativo y del ejecutivo y funcionalmente imparciales.

Para plantear el problema a analizar y justificar mi hipótesis de trabajo dividiré la investigación del siguiente modo. En primer lugar (II) analizaré al poder judicial en la doctrina de la separación de poderes, para luego (III) intentar responder por qué y respecto de quién deben ser independientes los tribunales de justicia, prosiguiendo (IV) con un estudio sobre la independencia judicial en la Constitución chilena de 1980, finalizando (V) con algunas conclusiones generales.

\section{EL PODER JUDICIAL EN LA DOCTRINA DE LA SEPARACIÓN DE PODERES}

Se puede hacer una asociación inescindible entre el constitucionalismo y la doctrina de la separación de poderes. El fundamento normativo para esta asociación es el artículo 16 de la Declaración francesa de los derechos del hombre y del ciudadano de agosto de 1789: "Toute société dans laquelle la garantia des droits n'est par asurée et la séparation des pouvoirs determineé, n'a point de constitution".

Si la cita obligada para rastrear los fundamentos de la doctrina de la separación de poderes es un texto del año 1789 , quiere decir ello que se trata de una construcción bastante moderna en la evolución de las sociedades políticas occidentales. Loewenstein señala que en realidad sólo corresponde a una protesta ideológica del liberalismo político contra el absolutismo de la monarquía en los siglos XVII y XVIII. De este modo, a su juicio, sólo el liberalismo constitucional identificó la libertad individual con la separación de los poderes. Para los antiguos, griegos y romanos, no fue preocupación ética la separación de funciones y su asignación a diferentes órganos estatales ${ }^{1}$. Se debe considerar por tanto la necesaria validez relativa y temporal de la doctrina de la separación de poderes. Sin embargo, como los postulados del constitucionalismo liberal moderno siguen informando a la mayoría de las organizaciones estatales contemporáneas, creo que vale todavía la pena revisar su justificación y configuración.

Si para comprender adecuadamente la doctrina de la separación de poderes hay que recurrir a los postulados de los autores ilustrados imbuidos

${ }^{1}$ Cfr. Loewenstein, Karl, Teoría de la Constitución (2a edición, Barcelona, Ariel, 1976), p. 56. 
del pensamiento político liberal, casi automáticamente se vienen en mente los nombres de Locke en Inglaterra y Montesquieu en Francia. Y si de un poder judicial como poder separado e independiente de los otros se trata, es este último autor la cita obligada.

Sin embargo, el fin de la separación de poderes en Montesquieu no es cuestión pacífica y puede dar lugar a confusiones. En efecto, intentando simplificar la realidad y la historia, uno podría pensar que del poder político absoluto donde el Monarca era titular de todo el poder y donde el principal momento de creación del Derecho es en la decisión judicial particular que hace este Monarca (se habla de este modo de un Estado jurisdiccional ${ }^{2}$ ), se pasa pacíficamente y sin solución de continuidad a un Estado de Derecho consagrando la división de poderes, donde el principal momento de creación del Derecho es en la actividad del parlamento (ley) para que luego su aplicación estricta y fiel sea realizada por jueces independientes del poder político. Uno podría pensar que este tránsito casi lineal se debe a los escritos de autores como Montesquieu y luego a las políticas y cambios institucionales llevados a cabo por los revolucionarios de 1789. En este sentido, podría sostenerse que Montesquieu es un ilustrado que al defender la separación de poderes y la independencia judicial lo que estaba haciendo era defender el Derecho creado mayoritariamente por la ciudadanía y que se expresa en la ley. Sin embargo, las lecturas de Montesquieu pueden ser muy diferentes de este planteamiento, dejando ver un semblante no propiamente ilustrado ni moderno.

La pregunta que uno puede formularse es qué buscaba Montesquieu con su doctrina de la separación de poderes. En realidad la tesis de que con tal doctrina buscaba reafirmar la voluntad general del pueblo expresada en la ley debe ser rechazada por varios motivos. En primer lugar, hay que entender que las luchas políticas del momento en que escribe nuestro autor no comprendían a todos los que habitaban tierras francesas, sino que sólo involucraban al Monarca y a la nobleza. Más tímidamente se puede incluir también a la burguesía. En este sentido, Montesquieu tuvo que defender a uno de esos tres poderes sociales. No todos los que habitaban tierras galas estaban en su mira.

En segundo lugar, tampoco se debe entender que Montesquieu quería defender imparcialmente la voluntad expresada en la ley, cualquiera que fuese el mandato que dispusiera esa ley. No defiende nuestro autor nada que pueda ser similar a una concepción positivista del Derecho, entendida

${ }^{2}$ Fioravanti, Maurizio, Estado y Constitución, en Fioravanti, Maurizio (coordinador), El Estado moderno en Europa. Instituciones y Derecho (traducción castellana de M. Martínez Neira, Madrid, Trotta, 2004), pp. 18-20. 
ésta como aquella que sostiene que la ley es válida en la medida que el enunciado normativo emane del órgano y bajo el procedimiento previsto por la ley, independientemente de lo que disponga esa ley. Montesquieu no puede ser considerado en este sentido positivista porque defiende un orden social dado y no quiere que éste cambie. En este sentido, a él no le es indiferente lo que disponga la ley. Ese orden social a defender se reparte entre el Monarca y el estamento noble al que él representa. Y desde luego en la época en la que él escribe la fuerza de la burguesía es todavía débil, por lo que en su análisis no entra este poder social. Entonces uno puede llegar a la conclusión que lo que él pretende con su teoría es dividir el poder entre el Monarca y el estamento noble para así evitar el despotismo. Se trata de construir una sociedad donde no exista una única fuente del poder normativo ni monopolio legítimo de la fuerza; una sociedad de poderes difusos, en algún sentido policéntrica. $\mathrm{Y}$ esa división del poder no tiene precisamente por fin, como se acostumbra proclamar, el triunfo de la libertad de los ciudadanos, sino más bien el aseguramiento de las prerrogativas aristocráticas ${ }^{3}$.

Alguna doctrina califica a Montesquieu como ilustrado y liberal en lo político ${ }^{4}$. Sin embargo, se señala por otros autores que al defender las prerrogativas de la nobleza, especialmente en las funciones judiciales que desarrollaban en los denominados parlaments, manifiesta así una actitud hostil hacia la racionalización del sistema jurídico y concibe al poder judicial no como un poder que desarrolla una función que modernamente podemos entender como función estatal, sino que es sostenedor de una función pre - política, de carácter social, que consiste en ser el garante de un orden de la sociedad, por lo que en definitiva se opone a los intentos del soberano absoluto de reformar este orden buscando mayor eficiencia 5 . En este sentido, el carácter ilustrado y liberal de Montesquieu es bastante cuestionable.

Pero la conclusión más importante que uno puede extraer de esta interpretación de los textos de Montesquieu que hace un sector de la doctrina, es que la génesis de la independencia judicial dentro de la doctrina de la separación de poderes, se ubica quizá en las antípodas de la cultura jurídica del Estado moderno. No se trataría, con Montesquieu, de tener jueces independientes del soberano legislador para que se respete la voluntad de la ley y en definitiva, uno podría agregar, la vida y propiedad 15.

${ }^{3}$ Vid. Rebuffa, Giorgio, La funzione giudiziaria (3a edición, Torino, 1993), p.

${ }^{4}$ Véase en este sentido Pedraz, Ernesto, Constitución, jurisdicción y proceso (Madrid, Akal, 1990), p. 15.

${ }^{5}$ Vid. Rebuffa, Giorgio, cit. (n. 3), p. 18. 
de los ciudadanos, sino que lo que busca dicha independencia del poder judicial es asegurar que el Monarca no pueda controlar esta parte del poder estatal que debe corresponder al estamento noble. Este orden de poderes se asegura evitando que el Monarca designe a los jueces y haciendo hereditarios los cargos judiciales. Se genera de este modo un poder del Estado por razones de sangre.

Luego, sin embargo, Montesquieu se contradice y termina por delinear un modelo de juez que no se corresponde con la idea de proteger a la nobleza como orden social determinado. En efecto, para él los jueces no debían ser permanentes ni estables. Rebuffa ${ }^{6}$ señala que en realidad no hay contradicción en esta parte, puesto que lo que se pretende evitar siempre, es que el poder legislativo, el soberano, no pueda elegir a los jueces, sino que éstos deben ser elegidos siempre por parámetros objetivos.

Como sea, es evidente que en Montesquieu hay paradojas. Resulta sorprendente que con sus escritos tan fuertemente inmersos en los problemas y en la ideología del Estado estamental, haya podido llegar a ser, hasta el día de hoy, el teórico de las organizaciones liberales fundadas sobre el sujeto único de derecho y la igualdad formal.

También es cuestionable que Montesquieu sea el artífice de la división de poderes. Desde luego, no puede considerarse que él conciba a tres poderes del Estado de un mismo modo, ya que sólo el ejecutivo y el legislativo son verdaderos poderes políticos que representan a las fuerzas sociales dominantes. El judicial no es poder en el sentido que no representa ningún sector social ${ }^{7}$. Por otra parte, la finalidad de Montesquieu no es dividir propiamente los poderes del Estado, sino fundamentalmente equilibrar a los grupos de individuos y de intereses de la sociedad a la que él pertenecía.

¿Cómo vincular entonces a Montesquieu con la doctrina típicamente liberal de la división de poderes? Uno podría concluir que la doctrina de Montesquieu fue el primer impulso para que con fines libertarios se organizara posteriormente el Estado como Estado de Derecho, lo que implica fundamentalmente reconocer en la Constitución la separación de los tres poderes estatales a los fines de que la vida, la libertad y la propiedad de los ciudadanos fuese asegurada ${ }^{8}$. Si bien Montesquieu abogaba en un primer momento para que esta organización del Estado respetase los privilegios

${ }^{6}$ Cfr. Rebuffa, Giorgio, cit. (n. 3), p. 22.

${ }^{7}$ Vid. Pedraz, Ernesto, cit. (n. 4), p. 29.

${ }^{8}$ Recuérdese que la Declaración de los Derechos del Hombre y del Ciudadano, de 1789, en su artículo 16, señalaba que: "una sociedad en la cual no esté asegurada la garantía de los derechos ni determinada la separación de los poderes no tiene una Constitución”. 
del estamento noble, los revolucionarios e ilustrados que hicieron suyos sus postulados aplicaron los beneficios de esta organización estatal para el ciudadano burgués; para la mayoría burguesa.

Tema discutible es el determinar si el judicial es realmente un poder, o si lo es, que lo sea en el mismo sentido que los otros dos. Algunos autores señalan que Montesquieu dividió el poder según las clases sociales dominantes en el momento histórico que le correspondió vivir. La división de poderes en Montesquieu no vendría a ser un problema jurídico sino político de relación de fuerzas, de poderes sociales, de modo que cada poder representa a un grupo social (el legislativo a la nobleza y burguesía, el ejecutivo al Rey) ${ }^{9}$. En cambio el Judicial representa a todos o, dicho de otro modo, no representa a ningún grupo social. En este sentido político, el judicial no es un poder ${ }^{10}$. Tenemos de este modo que el constitucionalismo moderno reconoce sólo dos poderes, en el sentido político apuntado; un legislativo y un ejecutivo.

Por otra parte, así como hay doctrina que sostiene que sólo hay dos poderes políticos en el Estado moderno y no tres, hay otra que indica que sólo es posible visualizar dos funciones estatales y no tres. En el Estado sólo se reconocerían las funciones de crear leyes y la de ejecutar leyes. Desde este punto de vista, la función de resolución de controversias debe ser considerada como parte de la función ejecutiva ${ }^{11}$. Esta posición bipartita del poder deja de lado otras funciones que, como veremos, son indispensables en el Estado de Derecho, como es la de control de los poderes políticos. Por ello debe ser rechazada.

Ahora bien, sin perjuicio de que se pueda aceptar que en Montesquieu los poderes sólo son dos, donde el judicial no figura como poder, otra cosa distinta es concordar en que el judicial es poder en otros sentidos. En primer lugar, si seguimos a Ludovico Mortara ${ }^{12}$, se puede sostener que se trata de un poder soberano; una manifestación de la soberanía nacional. Para este autor el poder soberano tiene como principal fin templar los excesos de la acción egoísta de los individuos y conservar así un equilibrio entre la libertad y los derechos de las personas. Ello es, a su juicio, el fin de la co-asociación y el secreto del bienestar de cada uno y de todos. Para este objetivo, la soberanía necesita del poder para hacer las leyes de modo

${ }^{9}$ Vid. Pedraz, Ernesto, cit. (n. 4), p. 29.

${ }^{10}$ Vid. Pedraz, Ernesto, cit. (n. 4), p. 29.

${ }^{11}$ Sobre este aspecto véase la relación de Troper, Michel, La separazione dei poteri e la storia costituzionale francese (Napoli, Edizioni Scientifiche Italiane, 2005), p. 44.

${ }^{12}$ Cfr. Mortara, Lodovico, Lo Stato moderno e la giustizia (Napoli, Edizioni Scientifiche Italiane, 1992), p. 31 y ss. 
tal de dar amparo a los derechos de todos. Pero para que las leyes puedan tutelar efectivamente los derechos de los coasociados, se hace indispensable la existencia de otro poder soberano encargado de hacerlas observar, aun coactivamente. Este tercer poder necesario para la soberanía nacional es precisamente el poder judicial ${ }^{13}$.

Pero es legítimo preguntarse ¿por qué necesita la soberanía nacional de otro poder para hacer cumplir las leyes? Mortara, inspirado naturalmente en las fórmulas ideadas previamente por Montesquieu para hacer frente a los gobiernos despóticos, señalaba que la aplicación de la ley considera en cada caso los derechos e intereses de un individuo, y si en esta sede se transportase el accionar antagónico entre facciones que es propio de un legislativo en una democracia representativa, ese poder legislativo se reservaría con ocasión del caso particular las luchas que habían surgido previamente en torno al principio general que inspira a la ley. De este modo, conservando el propio legislativo el poder de aplicar su producción normativa, cada facción política trataría de hacer prevalecer sus pareceres. En definitiva, la aplicación de toda ley a un caso concreto se transformaría en la elaboración de una nueva ley. Faltaría de este modo la garantía de igual tratamiento a todas las situaciones individuales que se encuentren en la misma posición, y el equilibrio de derechos que se había conseguido con las disposiciones de orden universal se esfumaría en su funcionamiento práctico ${ }^{14}$.

Pero aun concordando en que no debe ser el propio legislativo quien debe aplicar su producción normativa, uno podría señalar que basta a estos efectos que sea el ejecutivo quien se encargue de esa aplicación, por lo que la necesidad de un tercer poder, el judicial, tampoco se ve como necesaria. De hecho, como ya se indicaba, el ejecutivo tiene por fin principal, como su propio nombre lo indica, ejecutar las leyes. Mortara rechaza este argumento sosteniendo que al ejecutivo hay que entenderlo como el administrador de la sociedad. El ejecutivo administra; hace, por tanto, algo más que ejecutar leyes. En este sentido, si el ejecutivo dicta actos que pretenden administrar la sociedad, y si esos actos, por exigencia del principio de legalidad en un Estado de Derecho, deben ajustarse a la ley, tiene que haber un poder diferente que vigile y controle a ese poder en el cumplimiento de la ley. En este sentido, el ejecutivo en cuanto ente que administra, se pone en una situación similar a la de los individuos, en el sentido que deben realizar sus respectivos actos respetando la ley. Debe haber por tanto un tercer poder encargado que todo ello se cumpla ${ }^{15}$. De

\footnotetext{
${ }^{13}$ Mortara, Lodovico, cit. (n. 12), p. 31.

${ }^{14}$ Cfr. Mortara, Lodovico, cit. (n. 12), p. 33.

${ }^{15}$ Cfr. Mortara, Lodovico, cit. (n. 12), p. 59.
} 
acuerdo a esta argumentación, Mortara llega a concluir tres cosas. Que un Estado de Derecho necesita de la separación de poderes; que se necesita de un tercer poder denominado judicial, y que ese tercer poder necesita de una organización tal que garantice su autonomía respecto de los otros poderes ${ }^{16}$.

Ahora bien, que sea un poder soberano el judicial no significa que sea un poder político. Los jueces no representan, al menos formalmente, a ningún grupo social. No tienen el poder normativo de representar a ninguna facción dentro de la sociedad. Esto a su vez quiere decir que en una democracia representativa los jueces carecen de iniciativa política y de la competencia para la creación de normas jurídicas que vinculan a los demás poderes y a los ciudadanos con un carácter general. Que el judicial sea un poder soberano indica fundamentalmente que se trata de un poder jurídico, un poder en el Estado ${ }^{17}$. Dicho de otro modo, hay que concordar en que los jueces ejercen una de las funciones estatales.

¿Quiere decir lo anterior que a los jueces no puede atribuirse ningún tipo de actividad política? En un sentido estricto como el antes apuntado, debe quedar absolutamente claro que los jueces no son órganos políticos. Sin embargo, si se analiza el concepto de política desde otros puntos de vista, quizá ello deba ser aceptado. En primer lugar, se puede hablar de cierta politicidad en la actividad que realizan los jueces en orden a contribuir en el proceso en el cual los bienes vienen asignados en una sociedad determinada mediante providencias dotadas de autoridad ${ }^{18}$. Eduardo Aldunate destaca esta realidad al señalar que los jueces desarrollan una función que es quizá una de las políticamente más intensas, al decidir en definitiva sobre la libertad de los ciudadanos en su contacto con el Estado. Y luego agrega que los jueces trabajan además con un material que es político, ya que las leyes consagran decisiones políticas ${ }^{19}$.

Y luego está, claramente, el hecho que los jueces también crean derecho, aunque sea en un caso concreto y no con efectos generales. Esa creación de derecho por parte de los jueces apunta a que en el caso de lagunas, conceptos indeterminados o el llamado a principios o valores por el legislador, es el juez quien colmará la laguna o determinará el mandato legal o el principio o valor a aplicar. Esa es una realidad inevitable que no vale

${ }^{16}$ Cfr. Mortara, Lodovico, cit. (n. 12), p. 60.

${ }^{17}$ Vid. Pedraz, Ernesto, cit. (n. 4), p. 47.

${ }^{18}$ Vid. Guarnieri, Carlo, L'indipendenza della magistratura (Padova, Cedam, 1981), p. 44.

${ }^{19}$ Cfr. Aldunate, Eduardo, La independencia judicial. Aproximación teórica, consagración constitucional y critica, en Revista de Derecho Universidad Católica de Valparaiso 16 (1995), p. 23. 
mucho la pena discutir a estas alturas. Podrá discutirse si esta es la regla general o la excepción en un Estado de Derecho, pero ya nadie discute que los jueces terminan en ciertos casos por crear la regla jurídica.

Sin embargo, el poder creador de derecho de los jueces puede apuntar también a que las sentencias judiciales determinan autoritativamente la existencia, calificación jurídica u otro aspecto de una posición institucional determinada, y a consecuencia de la sentencia, esa posición institucional queda fijada para y con respecto a todos los casos. De este modo toda sentencia judicial pasa a formar parte del sistema jurídico y en este sentido produce efectos más allá del caso concreto ${ }^{20}$. Toda sentencia, en este sentido apuntado, produce por definición efectos generales. Ahora bien, en cuanto al contenido de las sentencias, éstas normalmente tendrán efectos relativos a las partes de la causa, aunque también puede tenerlos más allá de la partes de esa causa. Esto puede darse cuando así lo disponga la ley o bien cuando la realidad fáctica así lo imponga. En el primer caso tenemos las sentencias con efectos erga omnes, como ocurre normalmente con las que dictan los tribunales constitucionales. En el segundo caso, puede darse que un juez que ordena el cese de las emanaciones tóxicas de una empresa demandada por un vecino de una determinada ciudad, esa sentencia beneficiará a miles o quizá millones de personas que se verán beneficiadas por lo ordenado por el juez, aunque éste haya decidido una contienda particular sólo entre "Mengano y Celcus".

En estos sentidos y sólo en ellos que podemos hablar del judicial como un poder. $\mathrm{Y}$ desde luego esa condición de poder no está referida a ninguna estructura orgánica específica. No existe ninguna organización estatal que encarne al poder judicial en cuanto a poder jurídico que desarrolla la función judicial o jurisdiccional en el Estado. En realidad, hablando correctamente, al referirse a los tres poderes del Estado, éstos son el legislativo, el ejecutivo y los tribunales de justicia. La referencia al poder judicial como uno de los poderes del Estado, como es común en el lenguaje corriente, debe ser utilizada sólo como una abreviatura de todos los jueces o tribunales de justicia del país ${ }^{21}$.

Podemos concluir entonces que la doctrina de la separación de poderes buscó en sus orígenes combatir los gobiernos despóticos. Así se evitaba que un determinado grupo social interfiriera sobre los derechos e intereses

${ }^{20}$ Vid. Atria, Fernando, Inaplicabilidad y coherencia: contra la ideología del legalismo, en Revista de Derecho Universidad Austral de Chile 12 (agosto 2001): número especial "Justicia Constitucional”, pp.140 ss.

${ }^{21}$ Vid. en este mismo sentido Atria, Fernando, La improbabilidad de la jurisdicción, en La judicatura como organización (Santiago de Chile, Expansiva - Instituto de Estudios Judiciales, 2007), p. 43. 
de los demás. Con el tiempo dicha división buscó la consolidación de una sociedad regida por el imperio de la ley. Esto quiere decir que el poder legislativo debe crear el mandato legal; el poder ejecutivo debe ejecutar la ley $\mathrm{y}$ administrar la sociedad, y deben existir unos jueces para que el mandato de la ley se aplique irrevocablemente en los casos concretos sometidos a su conocimiento y decisión. Se construye entonces un Estado de Derecho en las democracias occidentales con dos poderes de representación popular que tienen la dirección política de la sociedad y un tercer poder, el judicial, que no tiene la conducción política de la sociedad y que debe velar porque los mandatos normativos se cumplan por todos; ciudadanos, poderes y órganos del Estado. Para que todo ello resulte, parece ser indispensable que los jueces sean independientes. A continuación pasaré revista al significado de la independencia judicial.

\section{III. ¿POR QUÉ Y RESPECTO DE QUIÉN DEBEN SER INDEPENDIENTES LOS TRIBUNALES DE JUSTICIA?}

Ante la pregunta del por qué deben ser independientes los tribunales de justicia, la respuesta que aparece obvia es la que sostiene que ello es así para garantizar que se respete el imperio de la ley. Debe haber alguien que esté en condiciones de controlar que se cumpla la ley. ¿Y quiénes deben cumplir la ley? Pues en primer lugar los ciudadanos. La ley se entiende como un instrumento de orden social.

Pero también deben cumplir la ley todos los órganos del Estado, especialmente aquellos que forman parte de la Administración del Estado. Es quizá con relación a la Administración del Estado donde la doctrina justifica más radicalmente la independencia de los tribunales de justicia. La potestad administrativa, expresa Mortara, es la que más activa y sensiblemente encarna la idea abstracta de soberanía y por eso mismo respecto de aquella es más probable que se den ocasiones de abuso ${ }^{22}$.

De independencia judicial sólo tiene sentido hablar en un Estado sometido a reglas legales generales y abstractas. Donde el poder no esté sometido a Derecho no aparece la necesidad de independencia de los tribunales. Podrá haber necesidad de imparcialidad, pero no de independencia. El Monarca podía ser imparcial frente a un súbdito en la resolución de un asunto que le afectaba. Pero desde el momento en que todo individuo, ciudadano o titular de un órgano estatal, ha de someterse al imperio de la ley, se requiere que el órgano juzgador tenga un status especial cual es de órgano independiente. Así, en un Estado de Derecho, el ejecutivo no

${ }^{22}$ Cfr. Mortara, Lodovico, cit. (n. 12), p. 59. 
puede dar órdenes a un juez de cómo proceder en un determinado caso, menos cuando en dicha causa figuran como parte órganos del gobierno o la administración del Estado ${ }^{23}$.

No basta, expresa Carl Schmitt, garantizar la independencia de los jueces para las causas civiles y penales donde aparecen como parte los ciudadanos. Esto nada tendría de particular y hasta en el Estado monárquico absoluto bien organizado se garantizó. Es que a su juicio el interés de la burguesía liberal en la lucha por el Estado de Derecho perseguía, fundamentalmente, un control judicial de los medios de poder del gobierno monárquico, y concretamente de la burocracia administrativa. Así se explica que muchos autores de Derecho público en el siglo XIX (al menos entre los alemanes como Bähr, entre otros ${ }^{24}$ ) hayan designado como Estado de Derecho sólo aquél en que hay un control judicial de la administración ${ }^{25}$.

El ejecutivo puede ser el principal agente de conculcación de los derechos de los ciudadanos. Por ello el constitucionalismo moderno establece como uno de sus postulados fundamentales el que es útil para la colectividad y necesario para la garantía de la libertad de cada uno, que la magistratura sea puesta en condiciones de ejercitar su función de manera autónoma e independiente de todo otro poder; en esto radica lo esencial. Y esa autonomía debe buscarse respecto de quien detenta el poder político, con especial consideración del ejecutivo ${ }^{26}$.

Pero si se considera como sinónimo de Estado de Derecho aquel Estado donde la administración está sujeta al control judicial, como proponían algunos iuspublicistas alemanes, uno podría concluir que muchos países europeos de tradición continental, como Francia y España, no tuvieron durante buena parte del siglo XIX un verdadero Estado de Derecho. Recién en 1872 en Francia se crea al interior del Consejo de Estado una instancia

${ }^{23}$ Cfr. Aldunate, Eduardo, cit. (n. 19), p. 12.

${ }^{24}$ Entiendo que los autores alemanes que cita Schmitt son de ideología liberal, porque también hay autores de Derecho público alemán que rechazan totalmente que la Administración pueda ser controlada por los tribunales de justicia. Así por ejemplo Juan Gaspar Bluntschli reclamaba porque el control de la Administración lo ejerciera esta misma o a lo más unos funcionarios al interior de la Administración bajo la forma judicial. Cfr. Bluntschli, Juan Gaspar, Derecho público universal, parte primera, teoría general del Estado (Madrid, F. Góngora y Compañía Editores, 1880), pp. 350 y ss.

${ }^{25}$ Cfr. Schmitt, Carl, Teoría de la Constitución (Madrid, Alianza Editorial, 1992), p. 143.

${ }^{26}$ Vid. Balboni, Enzo, Potere politico e funzione giurisdizionale: Il fondamento costituzionale, en La riforma dell ordinamento giudiziario tra indipendenza della magistratura e primato della politica (Milano, Giuffrè, 2006), p. 56. 
independiente de resolución de las controversias administrativas. Lo mismo sucede en España en el año 1888 con la ley Santamaría de Paredes.

Resulta contraproducente que en la Francia postrevolucionaria ${ }^{27}$ se haya sustraído del control judicial los actos de la administración que vulneraban los derechos o intereses de los ciudadanos. Las justificaciones para esta negativa son varias. Revisando la doctrina pertinente puedo agrupar en dos los principales argumentos para dicho rechazo. En primer lugar la propia doctrina de la separación de poderes; en segundo lugar, la ideología de los códigos decimonónicos, es decir, el positivismo formalista basado en el razonamiento jurídico silogístico.

\section{La exención de control jurisdiccional de la administración del Estado.}

a) La doctrina de la separación de poderes como justificación del rechazo al control jurisdiccional de los actos de la administración del Estado. Alguna doctrina justifica la incontrolabilidad jurisdiccional de los actos de la administración debido a que con ella se pondría en riesgo la esfera autónoma de actuación del ejecutivo. Un poder judicial con capacidad de controlar los actos administrativos lo convertiría indebidamente en un poder soberano ${ }^{28}$. Parece que esta posición asume, a diferencia de la posición que veíamos con Mortara, que el poder soberano sólo radica en los órganos políticos que ejercen activamente la soberanía nacional. Si se ha de controlar a la administración del Estado, pues tendrá que ser una sección de esa administración quien realice ese control. No puede ser el legislativo, en aras del principio de separación de poderes, aun cuando se trate también de otro poder soberano. Y no lo podrá hacer tampoco el poder judicial por cuanto no es poder soberano y de hacerlo, se rompería con la separación de poderes.

De un modo radical, la separación de poderes supone la no interferencia entre los distintos poderes. El poder judicial, en lo que nos interesa, no puede interferir en el actuar del parlamento ni en la del gobierno ni administración del Estado.

No hay que olvidar que en el Antiguo Régimen francés, los tribunales, los parlaments, se comportaban en la práctica como superiores jerárquicos de la administración. Entonces, es razonable pensar que los constituyentes de las primeras constituciones francesas (1791 y año III), con la incon-

${ }^{27}$ Sin perjuicio de que haya habido algunos intentos de someter a la administración del Estado al control y vigilancia de unos tribunales especiales con competencia administrativa. Se trató del proyecto Thuret, del año 1789.

${ }^{28}$ Vid. Bluntschli, Juan Gaspar, cit. (n. 24), pp. 350 ss. Lo mismo repite en Chile Lastarria. Vid. Lastarria, José Victorino, Estudios políticos i constitucionales (Santiago, Imprenta, Litografía i Encuadernación Barcelona, 1906), I, pp. 406 ss. 
trolabilidad de los actos de la administración por parte de los tribunales de justicia, quisieron evitar la sumisión de la administración a ellos. Su legislación seguramente está inspirada en el principio de la separación de poderes $^{29}$. El lema que se construye bajo este postulado de la separación de poderes es el famoso juger l'administration c'est encore administer.

b) El positivismo formalista y el silogismo judicial como justificación al rechazo del control jurisdiccional de los actos de la administración del Estado. Se ha intentado explicar la imposibilidad de los tribunales de justicia de controlar los actos de la administración del Estado en la ideología que está en los códigos postrevolucionarios; el positivismo formalista. Como los tribunales de justicia, en la concepción de Montesquieu, son concebidos como un no poder; un poder invisible y nulo, según la conocida frase de Montesquieu ${ }^{30}$, sus decisiones no determinan qué es Derecho, sino que éste le viene dado previamente con la decisión política contenida en la ley. El modo de operar del juez es mediante la construcción de silogismos judiciales. Para que pueda operar el silogismo judicial se requiere que el supuesto fáctico normativo esté completamente descrito en la ley.

Sin embargo, destaca Michel Troper ${ }^{31}$ que tratándose de actos de la administración del Estado, sólo algunas de las conductas constituían un verdadero supuesto fáctico normativo. Esto sucedía en Francia cuando las conductas administrativas estaban definidas como violación de una ley penal y cuando la competencia del administrador era conectada a una ley imperativa. Sólo en esos casos los tribunales estaban en condiciones de decidir. Al contrario, por ejemplo, el contencioso relativo a los tributos no podía ser atribuido a los tribunales, porque los impuestos directos eran de repartición. La repartición de los impuestos entre los distintos departamentos era efectuada por el cuerpo legislativo, es decir, pertenecía a los administradores del departamento. En todo ello se procedía con cierta discrecionalidad.

De este modo, en este tipo de contencioso, los jueces ordinarios no estaban en condiciones de enjuiciar porque no podían practicar un verdadero silogismo. De una parte, las administraciones inferiores no sólo aplicaban las leyes, sino también las órdenes de las autoridades superiores; de otra parte, no existía una ley que definiese la ilegalidad en el ejercicio de un poder discrecional y que determinase las sanciones por tal ilegalidad.

Si la Asamblea Constituyente hubiese redactado un Código Admi-

${ }^{29}$ Vid. Troper, Michel, cit (n. 11), p. 50.

${ }^{30}$ Cfr. Montesquieu, El espiritu de las leyes (Madrid, Biblioteca Auxiliar del Jurisconsulto y Publicista, 1845), p. 194.

${ }^{31}$ Cfr. Troper, Michel, cit (n. 11), pp. 190 ss. 
nistrativo completo, habría podido confiar a los jueces la resolución del contencioso administrativo. Ante la ausencia de este Código, atribuir a los jueces el poder de conocer de estas controversias habría estado en contradicción con la concepción de la sentencia - silogismo, y en definitiva, con la concepción pasiva y apolítica de la justicia.

Carl Schmitt secunda esta justificación. Sostiene al respecto que el ideal pleno del Estado burgués de Derecho culmina en una conformación judicial general de toda la vida del Estado. Para toda clase de diferencias y litigios, sea entre particulares o entre autoridades estatales entre sí o con los particulares, debía haber un juez y un procedimiento judicial capaz de resolverlas. Sin embargo, agrega, se olvida que este ideal supone siempre que deben existir leyes generales en vigor, pues el juez es independiente sólo bajo condición de que haya una norma de la que dependa. Allí donde esa norma falte, puede hablarse, a lo sumo, de un procedimiento de mediación, cuyo resultado práctico depende de la autoridad del mediador. Y si la importancia de la propuesta de mediación depende del poder del mediador, entonces no hay mediación auténtica, sino una decisión política más o menos ecuánime. A diferencia del Derecho privado, el Derecho público encuentra dificultades para su judicialización ${ }^{32}$.

Como se sabe, esta postura de Schmitt fue fuertemente contestada por Kelsen. Sostenía éste que la división entre administración y jurisdicción que ve libertad (o discrecionalidad) en la primera y sometimiento a la ley en la segunda, es lógicamente insostenible y esconde un postulado político que contradice el derecho positivo. En la discrecionalidad no están las diferencias, al menos sustanciales, entre actividad administrativa y actividad jurisdiccional. En ambas actividades se da este fenómeno. A lo más puede haber en esto una diferencia cuantitativa, mas no cualitativa ${ }^{33}$.

\section{Poder judicial y función jurisdiccional.}

Para un sector de la doctrina, esta idea de que la administración haya quedado sin control jurisdiccional en la Francia postrevolucionaria, no es tan clara. Es que cuando la Administración resuelve una contienda entre un particular y una sección de esa misma Administración, lo que está en ejercicio es la función jurisdiccional. Lo que ocurriría es que la Administración en ciertos casos, asumiría un rol diverso, cual órgano jurisdiccional. Se podría entender de este modo que en esta situación sí

${ }^{32}$ Cfr. Sснмitт, Carl, cit. (n. 25), pp. $144-145$.

${ }^{33} \mathrm{Cfr}$. Kelsen, Hans, Giurisdizione e amministrazione, en Geraci, Carmelo (editor), Il primato del parlamento (Milano, Giuffrè, 2002), p. 102. 
hay control jurisdiccional de la Administración, al asumir esta misma la función jurisdiccional.

Juzgar, dice Duguit, es hacer constar la existencia de una regla de derecho o de una situación de derecho. El Estado, de este modo, se ve obligado a intervenir en tal sentido cuando la regla de derecho ha sido violada o cuando la situación jurídica es negada o desconocida en su existencia o extensión. Cuando corresponda, dispondrá dicho Estado las medidas necesarias para asegurar el respeto debido a su decisión ${ }^{34}$. Pues para Duguit en esto consiste la función jurisdiccional.

No cabe duda, agrega Duguit, que la autoridad judicial ejerce sobre todo y fundamentalmente la función jurisdiccional, pero ni es ella sola la que la ejerce, ni ejerce toda la función jurisdiccional. En Francia, agrega, y en muchos otros países, la autoridad administrativa ejecuta muchos actos jurisdiccionales. Y para entender qué es la función jurisdiccional, pues debe situarse para ello en el punto de vista material de la función, esto es, haciendo total abstracción del carácter de los organismos, de los agentes, de las autoridades que ejercen esta función ${ }^{35}$. Duguit pone por ejemplo el caso del Senado en Francia, donde se transforma en ocasiones en Alta Corte de Justicia. En este caso, deja ser una asamblea política para convertirse en una jurisdicción ${ }^{36}$. Lo mismo sucedería, si seguimos a Duguit, cuando un ministro decide con fuerza ejecutoria un determinado asunto. Ese funcionario del gobierno ejercería en este caso jurisdicción.

Esta concepción de la función jurisdiccional que nos da el autor francés, es coherente con la que expone un sector de la doctrina procesalista italiana de comienzos del siglo XX. Así Chiovenda señalaba que la jurisdicción no puede definirse por el órgano ni por las garantías exteriores. La jurisdicción se define por la función desarrollada. De este modo, a su juicio, en Italia, las competencias contenciosas del ministro en materia de quintas y de aduanas eran funciones jurisdiccionales. Poco importa la forma exterior del agente y del procedimiento por el cual se decide. No es relevante, para Chiovenda, si el agente juzgador es o no independiente del poder político y si se decide previo contradictorio entre partes ${ }^{37}$. Lo único relevante es la capacidad para resolver una litis ${ }^{38}$.

${ }^{34}$ Cfr. Duguit, Leon, Manual de Derecho Constitucional (Granada, Comares, 2005), pp. 79 ss.

${ }^{35}$ Cfr. Duguit, Leon, cit. (n. 34), p. 103.

${ }^{36}$ Cfr. Duguit, Leon, cit. (n. 34), p. 423.

${ }^{37}$ Cfr. Chiovenda, José, Principios de Derecho Procesal Civil (Madrid, Reus, 1977), I, p. 370.

${ }^{38}$ Vid. Carnelutti, Francesco, Derecho y proceso (Buenos Aires, Ediciones Jurídicas Europa-América, 1971), p. 62. 
Sin embargo, otro sector de la doctrina francesa señala que en estos casos, como los del ministro que decide un asunto, no se está frente a una actividad jurisdiccional, sino administrativa. A este respecto, Laferrière señala que las atribuciones que tienen los ministros para resolver reclamos que presentan los particulares frente a decisiones adoptadas por un funcionario del propio ministerio, deben ser consideradas como un recurso administrativo jerárquico y en virtud de él, el ministro puede conocer cuestiones de hecho, de oportunidad, de equidad y contenciosas. Se trata de decisiones ministeriales en materia contenciosa, las que son inherentes a su derecho de decisión administrativa. Señala además que a su juicio es imposible administrar los asuntos del Estado sin conocer permanentemente de cuestiones de derecho y justicia, que son esencialmente contenciosas ${ }^{39}$.

El Consejo de Estado, en un primer momento, implícitamente atribuyó a estas funciones del ministro una naturaleza jurisdiccional, en una posición cercana a la de Duguit. Sin embargo, autores como Serrigny, Bouchené-Lefer y Aucoc cuestionaron esta tesis, denominándola doctrina del ministro-juez, señalando que esas atribuciones si bien son análogas a las jurisdiccionales por cuanto la decisión tiene fuerza ejecutoria, en definitiva son diferentes. Las diferencias principales entre el juez y el ministro, plantea Laferrière, son que el juez no puede conocer de oficio y el ministro sí; el carácter de tercero imparcial del juez y de parte interesada del ministro y que el juez no puede volver sobre sus decisiones, pero el ministro $s^{40}{ }^{40}$.

Esta doctrina tuvo su reflejo en la decisión del Consejo de Estado del ańo 1889, conocido como arrêt Cadot, donde el Comisario de Gobierno Jagerschmidt señaló que la administración puede tomar decisiones administrativas ejecutorias, aun con base en un contencioso previo, pero se trata siempre de decisiones administrativas y no jurisdiccionales. Luego esa decisión administrativa puede ser discutida ante un órgano jurisdiccional $^{41}$.

A fin de cuentas, a lo mejor todo esto puede tratarse de una mera cuestión lingüística. Si seguimos a Duguit, quizá se pueda convenir en que la administración puede dar una decisión jurisdiccional, la que posteriormente podrá ser revisada por otra decisión jurisdiccional de la autoridad judicial. Aquí lo único que importaría es que esa decisión

${ }^{39}$ Cfr. LAFERrière, Édourd, Traité de la jurisdiction administrative et de recours contentieux (edición facsimilar del original de 1887, París, LGDJ, 1989), I, pp. 395 ss.

${ }^{40}$ Cfr. Laferrière, Édourd, cit. (n. 39), pp. 403 - 404.

${ }^{41}$ Vid. Long, Marceau et al, Les grands arrêst de la jurisprudence administrative (15ª edición, París, Dalloz, 2005), pp. 36-38. 
jurisdiccional de la administración, si vulnera el ordenamiento jurídico o los derechos e intereses de los ciudadanos, pueda ser controlada por la decisión jurisdiccional de los tribunales de justicia. Ese control judicial debe ser pleno, es decir, debe permitir conocer desde su inicio de todos los hechos esgrimidos por las partes, aceptando todos los medios de prueba legales ofrecidos por éstas y dando lugar posteriormente a la interposición de todos los recursos procesales ante otros tribunales que disponga el orden jurídico respectivo.

Sin embargo, para algunos autores y legislaciones esta decisión que da la autoridad administrativa no es una decisión jurisdiccional sino una vía administrativa previa a la vía jurisdiccional. Se trata de los recursos jerárquicos que existen normalmente al interior de la administración. Para Duguit, por el contrario, se trataría de una decisión jurisdiccional dada por la administración que puede ser previa al control jurisdiccional que en definitiva desarrollará la justicia.

Ahora bien, la tesis de que la decisión de la administración en estas materias es una decisión administrativa previa a la actividad jurisdiccional es la que se ha terminado de imponer en la mayoría de los países, al menos en los de tradición jurídica continental.

Podemos concordar entonces que si el control que realiza la administración a sí misma, sea que se considere actividad jurisdiccional o bien un recurso jerárquico administrativo, permite posteriormente un total y exhaustivo control por parte de tribunales independientes, la verdad es que la discusión termina siendo más terminológica que sustancial. Por el contrario, si la actividad de control que realiza la administración de sí misma es considerada un sustituto de la actividad que deben realizar tribunales de justicia independientes, o bien, una primera instancia de esa actividad judicial, pues ahí se rompe con un Estado de Derecho que consagra la separación de poderes y la independencia judicial como garantía de los derechos de las personas.

Sin embargo, como veremos, el considerar bajo cualquiera de los supuestos antes esbozados que la administración ejerce parte de la función denominada jurisdiccional, ello en definitiva trae consecuencias negativas para la legitimidad de las decisiones estatales y para la libertad de los ciudadanos. En este sentido, se hace más aconsejable entender que la función jurisdiccional sólo puede ser desarrollada por un poder estatal: los tribunales de justicia.

Para Duguit, no existen dos funciones a este respecto en el Estado: una función jurisdiccional y otra de carácter judicial. Sólo existe la función jurisdiccional. El empleo adecuado del término judicial, a su juicio, es para referirse a un tipo de autoridad que existe en Francia y en la mayoría de las 
democracias modernas, que es distinta y legalmente independiente de la autoridad administrativa. Lo jurisdiccional entonces aparece referido a una función del Estado y lo judicial a un conjunto de órganos del Estado ${ }^{42}$.

Alessandro Pizzorusso está de acuerdo en que hay que distinguir entre función jurisdiccional y poder judicial. Es decir, está de acuerdo que en el Estado de Derecho hay una sola función a este respecto: la jurisdiccional. Semánticamente, dichos términos claramente indican actividad en un caso y, en el otro, un complejo de sujetos. Sin embargo, agrega que están fuertemente ligadas, porque los órganos judiciales son aquellos que al menos por regla general ejercitan actividad jurisdiccional, mientras que esta última, a su vez, se identifica normalmente por la actividad cuyo ejercicio es demandado a los órganos judiciales. De este modo, esta correspondencia entre función y poder judicial resulta fundamental a los fines del encuadramiento general de esos sujetos y de esta actividad dentro de los poderes y funciones del Estado ${ }^{43}$.

Pizzorusso se alejará de Duguit al definir la función jurisdiccional, porque a juicio del primero la cuestión formal u orgánica parece comprender parte de la definición material de la función. Así, si para Duguit la función jurisdiccional consiste en hacer constar el Estado la existencia y la extensión de una regla de derecho o de una situación de derecho, en caso de violación o de contienda, y disponer las medidas necesarias para asegurar el respeto debido a su decisión ${ }^{44}$, para el autor italiano la función jurisdiccional comprende el conjunto de las actividades de aplicación de la ley que son ejercitadas por sujetos agentes en posición de terzietà respecto a dos o más partes, elegidos en virtud de especiales requisitos que los hacen particularmente idóneos para el ejercicio de estas funciones y que operan en el respeto de especiales normas procesales previstas en relación a los diversos tipos de proceso (civil, penal, etc.) ${ }^{45}$.

De este modo, para Pizzorusso no se puede confundir la actividad jurisdiccional de control de los actos de la administración del Estado, con la actividad de control de legitimidad o mérito que realizan órganos que son administrativos (como la corte de cuentas, comisiones y comités de

${ }^{42}$ Cfr. Duguit, Leon, cit. (n. 34), p. 103. En esto parece también coincidir en tiempos más recientes Michel Troper, quien considera como sinónima las denominadas funciones jurisdiccional y judicial. Es decir, considera que se trata de una sola función del Estado. Cfr. Troper, Michel, cit. (n. 11), p. 43.

${ }^{43}$ Cfr. Pizzorusso, Alessandro, L'organizzazione della giustizia in Italia. La magistratura nel sistema politico e istituzionale (Torino, Einaudi, 1990), p. 5.

${ }^{44}$ Cfr. Duguit, Leon, cit. (n. 34), p. 79.

${ }^{45}$ Cfr. Pizzorusso, Alessandro, cit. (n. 43), p. 7. 
control). Esta última constituye ejercicio de la función administrativa y no jurisdiccional ${ }^{46}$.

Es de destacar que en la concepción de Pizzorusso hay dos elementos que Duguit catalogaría de formales, pero que para el primero definen la actividad jurisdiccional. Se trata, en primer lugar, de la existencia de un tercero que falla una controversia jurídica donde, además, se ven involucradas dos partes. Ese tercero debe ser independiente respecto de los otros poderes del Estado. La independencia del juez, por tanto, es una característica fundamental de la actividad jurisdiccional ${ }^{47}$.

En un sentido similar Andrés Ibáńez sostiene que para poder caracterizar a la jurisdicción tal y como resulta concebida en los sistemas constitucionales modernos, hay que atender necesariamente a las peculiaridades de la posición estatutaria del juez. En particular, agrega, a su condición de tercero frente a las demás instancias de poder. Se debe atender a su autonomía política, a la exención de toda subordinación, que es lo que lo hace independiente; e independiente para y solo para la aplicación igualitaria de la ley al caso concreto como sujeto imparcial ${ }^{48}$. Será independiente el juez en la medida que esté libre de influencias e intervenciones extrańas tanto si provienen del gobierno, del parlamento, del electorado o de la opinión pública ${ }^{49}$.

En realidad, el ideal de un Estado de Derecho que reconoce la independencia judicial no tolera que el poder judicial comparta el ejercicio de la jurisdicción con otros poderes. La independencia judicial, expresa Loewenstein, conduce inevitablemente a la exigencia de que los tribunales de justicia detengan el monopolio de la administración de justicia. Esto no supone tan solo la ilegalidad de todos los tribunales excepcionales, siempre y cuando en la Constitución no estén expresamente previstos como tribunales especiales (caso de los tribunales constitucionales, por ejemplo), sino que excluye también todas las funciones judiciales por parte del gobierno y del parlamento ${ }^{50}$.

Cuando los órganos de la administración del Estado dictan sentencias aplicando aun coactivamente una norma jurídica a un caso concreto, acti-

${ }^{46}$ Cfr. Pizzorusso, Alessandro, cit. (n. 43), p. 12.

${ }^{47}$ Vid. Pizzorusso, Alessandro, cit. (n. 43), p. 22; Guarnieri, Carlo, cit. (n. 18), p. 29.

${ }^{48}$ Cfr. Andrés IbáÑEz, Perfecto, Poder judicial y juez en el Estado constitucional de Derecho. El sistema del Consejo en La experiencia jurisdiccional: Del Estado legislativo de Derecho al Estado constitucional de Derecho (Madrid, Consejo General del Poder Judicial, 1999), p. 18.

${ }^{49}$ Vid. Loewenstein, Karl, cit. (n. 1), p. 295.

${ }^{50}$ Cfr. Loewenstein, Karl, cit. (n. 1), p. 296. 
vidad que para Duguit sería jurisdiccional, tal práctica dice Loewenstein no haría tan sólo levantar a Montesquieu de su tumba, sino que trae consigo el planteamiento de un serio conflicto con el monopolio judicial de los tribunales, poniéndose en jaque al Estado Democrático de Derecho. De máxima relevancia en un Estado de Derecho es que la administración sea controlada por tribunales auténticamente independientes, importando poco si se realiza por medio de tribunales ordinarios o administrativos ${ }^{51}$ (tribunales del contencioso - administrativo).

Tenemos de este modo que los tribunales de justicia deben ser independientes de los poderes políticos, sea del gobierno como del parlamento. Sólo así se permite el respeto de la ley para la sobrevivencia de los derechos de los ciudadanos.

En definitiva, a efectos de consolidar un Estado de Derecho eficiente, se hace aconsejable excluir de los poderes políticos la función jurisdiccional. $\mathrm{Ni}$ siquiera aun cuando se trate de una mera cuestión terminológica se hace aconsejable entender que dichos poderes políticos ejercen la función jurisdiccional. Podrán tener facultades juzgadoras o resolutorias, pero la función jurisdiccional sólo la deben ejercer tribunales de justicia independientes de los poderes políticos.

3. La función jurisdiccional de control de las actuaciones de los órganos políticos.

Con lo dicho hasta acá, queda en evidencia que en un Estado de Derecho una de las funciones que cumplen los tribunales de justicia es la de controlar la juridicidad de la actuación de los otros poderes del Estado. Los jueces no se limitan a resolver controversias jurídicas de carácter temporal entre particulares. Hacen eso, evidentemente; pero hacen bastante más que eso.

La doctrina es clara a este respecto. Con un carácter general e histórico Kelsen señala que el significado político de la independencia judicial era la limitación del poder absoluto del príncipe ${ }^{52}$. Giorgio Rebuffa sostiene uno de los fines de la independencia de los jueces es permitir que la actividad jurisdiccional funcione como control sobre la actividad de los otros poderes, garantizando así la legalidad ${ }^{53}$. Para que el juez pueda controlar a los demás poderes, es evidente que no debe ser removible de su cargo por esos poderes. A través de esta inamovilidad se ve reforzada la función de control del juez. Y si el juez desarrolla una función de control, se hace

\footnotetext{
${ }^{51}$ Cfr. Loewenstein, Karl, cit. (n. 1), p.308.

${ }^{52}$ Cfr. Kelsen, Hans, cit. (n. 33), p. 133.

${ }^{53}$ Cfr. Rebuffa, Giorgio, cit. (n. 3), p. 85.
} 
evidente la incompatibilidad del cargo judicial con otros cargos cuya permanencia dependa del gobierno o la administración, o del parlamento, y que pueden generar una relación de dependencia o interés económico para el juez ${ }^{54}$.

La función de control de los jueces ha cambiado su fisonomía y rol institucional. Es evidente que en un Estado Democrático de Derecho el juez no puede asumir iniciativas políticas en el sentido de definir, ni siquiera con un carácter relativo, qué es lo exigible jurídicamente en una determinada situación. Esa definición le corresponde a los poderes políticos representativos. Sin embargo, aun conservado este rol en cierto modo pasivo, se hace evidente que los poderes del juez en la sociedad actual tienen una trascendencia política indudable y afectan a ámbitos especialmente delicados del sistema democrático: las decisiones judiciales se refieren al sistema electoral, mantienen el control penal de los políticos, vigilan la actuación de la Administración ${ }^{55}$, etcétera. La importancia del control judicial se pone de manifiesto especialmente en el caso del control de la actuación de la administración por parte de los jueces, lo que en definitiva no deja de ser más que una lucha contra las inmunidades del poder ${ }^{56}$.

Algunos autores señalan que esta situación pone en evidencia la característica de un verdadero poder que tienen los jueces en las sociedades contemporáneas. Otros quizá van más allá de la definición de poder de los jueces para definirlos como órganos de garantía. En la primera situación encontramos a Loewenstein, para quien es tal el poder que detentan los jueces, que llega a ser superior al del gobierno y parlamento. Esto es muy claro cuando los jueces tienen el poder de supervisar y comprobar la concordancia de las acciones del poder ejecutivo con su base legal y cuando tienen la competencia para el control de la constitucionalidad de las leyes emitidas por el gobierno y el parlamento. Además, puede darse el caso que se instituya a los jueces como árbitros de los conflictos que se dan entre los poderes del Estado ${ }^{57}$.

Giovanni Giacobbe sostiene, desde otra perspectiva, que el judicial ha

${ }^{54}$ Vid. Aldunate, Eduardo, cit. (n. 19), p. 14.

${ }^{55}$ Hay otras propuestas en materia de control de los poderes políticos, que no entrega a los jueces el control de sus actos, sino a un nuevo poder o autoridad. Destaca a este respecto la propuesta de Bruce Ackerman, quien postula la creación de una autoridad de la integridad, al margen de la trinidad tradicional de los poderes, entidad que debería asumir el control de los actos de los poderes estatales, a fin de controlar la corrupción. Vid. Ackerman, Bruce, La nuova separazione dei poteri. Presidenzialismo e sistemi democratici (Roma, Carocci, 2003), pp. 73 ss.

${ }^{56}$ Vid. Ordóñez, David, Jueces, derecho y política. Los poderes del juez en una sociedad democrática (Navarra, Thomson Aranzadi, 2004), p. 70.

${ }^{57}$ Cfr. Loewenstein, Karl, cit. (n. 1), p. 305. 
ido perdiendo el rol de poder del Estado para asumir una nueva función cual es la de garantía, aun respecto de los órganos del Estado y, también, en contraposición al Estado aparato. Todo ello debe darse así cuando las funciones del ejercicio estatal incidan sobre los derechos de la personas ${ }^{58}$. Los tribunales vendrían a ser unos especiales órganos de garantía.

La función de control la extrapola Pizzorusso a una función más general cual es la de racionalización del sistema constitucional. Señala el profesor de Pisa que la función jurisdiccional constituye una forma de racionalización del sistema constitucional, tendiente a asegurar el respeto del principio constitucional del Estado de Derecho. Tal racionalización, a su juicio, representa la contribución que a la vida política y social del país da la cultura jurídica considerada en su conjunto, la que resulta del trabajo de los jueces, de los abogados y los estudiosos del derecho. Para poder cumplir esa función de tutor del Estado de Derecho, agrega, se debe garantizar la independencia de los jueces ${ }^{59}$.

Para materializar este rol de control jurídico bajo el principio de separación de poderes, sostiene Aldunate, la función jurisdiccional debe encontrarse disociada tanto material como orgánicamente de las demás funciones y órganos a controlar: de la función de gobierno y administración, y de la función nomogenética ${ }^{60}$.

La consecuencia de este rol de control jurídico que han asumido los jueces, y que en realidad es lo que históricamente justificó su creación en régimen de independencia, es que no puede concebirse el ejercicio de la función jurisdiccional por órganos vinculados a los poderes estatales objeto del control. No puede de este modo entenderse que la administración o el parlamento ejerzan jurisdicción en materias en las que aparezcan ellas interesadas. No puede de este modo la administración conocer de una contienda con un particular sobre materias de impuestos, aduanas, concesiones, etcétera.

Por todo ello no es aceptable la tesis que sostenía Duguit de definir a la función jurisdiccional sólo desde un punto de vista material, sin importar el sujeto o agente que la debe desarrollar. Con tal concepción cae toda la construcción y fundamento del Estado de Derecho. Y si se tratase de una cuestión meramente terminológica, pues ella confunde al ciudadano y deslegitima la actuación del Estado. Por ello no debe ser seguida.

Debemos entender por tanto que la función jurisdiccional es una de

\footnotetext{
${ }^{58} \mathrm{Cfr}$. Giacobbe, Giovanni, Autonomia della Magistratura, indipendenza del giudice, poteri del Ministro di Grazia e Giustizia en L'indipendenza della giustizia, oggi (Milano, Giuffrè, 1999), p. 170.

${ }^{59}$ Cfr. Pizzorusso, Alessandro, cit. (n. 43), p. 93.

${ }^{60}$ Cfr. Aldunate, Eduardo, cit. (n. 19), p. 17.
} 
las funciones que desarrolla el Estado encomendada en régimen de monopolio a tribunales de justicia independientes e imparciales. Esencial a esa independencia e imparcialidad será contar con jueces que no reciban instrucciones de otros poderes del Estado, que no puedan ser removidos por esos otros poderes y que fallen según lo que el Derecho prescribe. Sólo así se logra un juez imparcial, es decir, un juez que actúa con estricta fidelidad a la ley y nada más que a la ley. En el juicio del juez no debe concurrir ninguna otra pasión que no sea la aplicación desapasionada de las normas formales y ningún otro interés que no sea la búsqueda desinteresada de rectitud legal ${ }^{61}$. Sólo así tenemos un juez imparcial.

De este modo entonces, hay que entender que la administración del Estado ya no puede ejercer jurisdicción, ya que esa función sólo pertenece a los tribunales de justicia. Se trata de que el poder del Estado se especialice y se divida entre distintos órganos. Esa articulación en diversos ciclos funcionales de la organización del Estado, de modo tal que un mismo órgano no pueda desarrollar contemporáneamente, en el mismo ciclo, funciones diversas, constituye una enorme garantía para el ciudadano y, a su vez, un eficaz instrumento de organización del Estado ${ }^{62}$. Esta idea de que cada órgano desarrolle una sola función jurídica del Estado es el primer elemento de la teoría de la separación de poderes. Michel Troper habla del principio de la separación de las funciones o especialización de los órganos ${ }^{63}$. Y agrega que se observaría una derogación del principio de la especialización toda vez que un órgano ejercita una función o una parte de la función que no le es propia ${ }^{64}$.

Si en el Antiguo Régimen administrar y juzgar eran lo mismo, y si dicha actividad era desarrollada por un mismo poder ${ }^{65}$, ha llegado el momento de decir que la administración ya no puede desarrollar la función jurisdiccional. La administración podrá resolver y ejecutar asuntos, pero ello siempre será actividad administrativa y no jurisdiccional.

${ }^{61}$ Vid. Schedler, Andreas, Argumentos y observaciones: De criticas internas y externas a la imparcialidad judicial en Isonomia 22 (2005) abril, p. 71.

${ }^{62} \mathrm{Vid}$. Spadaro, Antonino, Il fenomeno della pubblicizzazione degli interessi privati e di riflesso, della privatizzazione degli interessi pubblici: Una piccola contribuzione sulla crisi dell' etica pubblica costituzionale en Diritto e potere nell Italia di oggi (Torino, Giappichelli, 2004), 16.

${ }^{63}$ Cfr. Troper, Michel, cit. (n. 11), p. 19.

${ }^{64}$ Cfr. Troper, Michel, cit. (n. 11), p. 19.

${ }^{65}$ Este argumento lo desarrollo más latamente en mi trabajo La Administración Pública ante los tribunales de justicia chilenos en Revista Chilena de Derecho 33 (2006) 1, pp. $17-23$. 


\section{LA INDEPENDENCIA JUDICIAL EN LA \\ “CONSTITUCIÓN" CHILENA DE 1980}

1. Recepción en el Derecho chileno de la doctrina de la separación de poderes.

La Constitución de 1980 (en adelante CPR.), así como las constituciones chilenas del siglo XIX y XX ${ }^{66}$, residencia en el poder judicial, que es sólo como decíamos una abreviación para referirse a los tribunales de justicia creados por ley, el ejercicio de la función jurisdiccional. El capítulo VI CPR: Poder Judicial, en su artículo 76 señala que: "La facultad de conocer de las causas civiles y criminales, de resolverlas y de hacer ejecutar lo juzgado, pertenece exclusivamente a los tribunales establecidos por ley. Ni el Presidente de la República ni el Congreso pueden, en caso alguno, ejercer funciones judiciales, avocarse causas pendientes, revisar los fundamentos o contenido de sus resoluciones o hacer revivir procesos fenecidos". He aquí una clara consagración de la doctrina de la separación de poderes y de la independencia del poder judicial.

Sin embargo, la situación se viene a complicar desde el momento que la parte dogmática de la Constitución (artículo 19 No 3 inciso 5० CPR.) garantiza que: "Toda sentencia de un órgano que ejerce jurisdicción debe fundarse en un proceso previo legalmente tramitado. Corresponderá al legislador establecer siempre las garantias de un procedimiento y una investigación racionales y justos".

Tenemos así que en la parte orgánica de nuestro texto constitucional se habla de poder judicial, tribunales de justicia y función judicial (artículo 76 CPR.). En la parte dogmática se habla de órgano que ejerce jurisdicción y habrá de entenderse por tanto que se reconoce una función jurisdiccional (artículo 19 No 3 inciso 5o CPR.). El texto constitucional chileno a la única función a la que se refiere expresamente es a la judicial, alejándose en esto de aquella doctrina ${ }^{67}$ que señalaba que la función es la jurisdiccional y el poder es el judicial.

Hay que decir que la mayoría de la doctrina nacional está conteste en que el ejercicio de la jurisdicción no está reservado en la Constitución de 1980 en exclusiva a los tribunales de justicia que integran el poder judicial. Para ello recurren a la historia fidedigna del artículo 19 No 3 inciso $5^{\circ}$ CPR. En efecto, la Comisión de Estudios de la Nueva Constitución (CENC), en su sesión No 103, dejó establecido que órgano que ejerce

${ }^{66}$ Vid. Navarro, Enrique, La teoría general de la división de poderes en la Constitución de 1980 en Revista de Derecho Universidad Católica de Valparaiso, XIV (1991 - 1992), pp. 202 ss.

${ }^{67}$ Como era el caso de Duguit y Pizzorusso. 
jurisdicción es todo órgano que resuelve una controversia en el orden temporal, sean tribunales ordinarios, administrativos, Contraloría General de la República, Impuestos Internos, tribunales arbitrales, etcétera. Además, en concordancia con lo anterior, un sector de la doctrina seńala que el término sentencia que emplea la disposición no se refiere exclusivamente a la sentencia judicial, en el sentido técnico procesal, sino a toda "resolución" de cualquier autoridad que le corresponda conocer, resolver y hacer ejecutar lo juzgado en relación a un asunto civil o criminal, es decir, que ejerza jurisdicción ${ }^{68}$.

Para esta doctrina órgano que ejerce jurisdicción y tribunal de justicia vienen a ser lo mismo. Y lo importante no es la consideración del órgano sino la función que desarrollan. Si los órganos, del tipo que sean, desarrollan la función jurisdiccional, es porque están siendo considerados como tribunales de justicia. Esta es la posición de Juan Colombo, una de las más conocidas en nuestro medio y de decisiva influencia en nuestra doctrina y jurisprudencia. Sostiene este autor que "la función es la que determina al órgano y no el órgano a la función; por ello [...] los órganos por medio de los cuales la jurisdicción se pone en movimiento pertenecen a veces al orden administrativo y otras, las más, al Poder Judicial, sin que ello altere la función que les ha sido encomendada" ${ }^{69}$.

Colombo sigue en su planteamiento posiciones muy similares a las que analizamos con Duguit y Chiovenda. Para comprender mejor esta posición, hay que considerar que esta doctrina nacional entiende por jurisdicción el poder - deber que tienen los tribunales para conocer y resolver por medio del proceso y con efectos de cosa juzgada los conflictos de intereses de relevancia jurídica que se promueven en el orden temporal, dentro del territorio de la República y en cuya solución les corresponde intervenir ${ }^{70}$.

De conformidad con lo expresado anteriormente, se puede afirmar que para esta posición doctrinal cualquier órgano autorizado por la ley para resolver conflictos de intereses de relevancia jurídica del orden temporal es un tribunal de justicia. Por tanto, pueden ejercer jurisdicción los tribunales de justicia, los órganos legislativos o los que forman parte de la administración del Estado, con tal que la ley los habilite para ello.

Sin embargo, si ello es así, surge inmediatamente la cuestión de cómo se puede conciliar esta tesis con la prohibición establecida por el artículo 76 CPR. dirigida al Presidente de la República y al Congreso Nacional para

\footnotetext{
${ }^{68}$ Por todos véase Verdugo, Mario - Pfeffer, Emilio / Nogueira, Humberto, Derecho Constitucional (Santiago, Editorial Jurídica de Chile, 1994), I, p. 216.

${ }^{69}$ Colombo, Juan, La competencia (2a edición, Santiago, Editorial Jurídica de Chile, 2004), p. 20.

${ }^{70}$ Vid. Colombo, Juan, cit. (n. 69), p. 45.
} 
ejercer funciones jurisdiccionales. La respuesta que da la doctrina basada en la historia fidedigna de la norma viene a decir que esa prohibición se establece taxativamente para esos órganos, es decir, específicamente para el Presidente de la República y para el Congreso Nacional, pero no para sus subordinados o ramas. Es decir, ni el Presidente de la República ni el Congreso Nacional pueden ejercer jurisdicción, pero sí lo podrían hacer un ministro de Estado o un director o jefe de servicio o bien el senado o la cámara de diputados ${ }^{71}$.

Como lo expresa Pantoja, en la Comisión de Estudio de una Nueva Constitución se había pensado redactar el actual artículo $76 \mathrm{CPR}$. indicando que: "Ninguna autoridad puede, en caso alguno, ejercer funciones judiciales, avocarse causas pendientes, revisar los fundamentos o contenidos de sus resoluciones o hacer revivir procesos fenecidos". La propuesta fue rechazada porque, como hizo ver el Presidente de la Comisión de Estudio, don Enrique Ortúzar Escobar, habría importado la derogación de todos los tribunales especiales que existían en ese momento como era el caso del director de impuestos internos, el superintendente de aduanas, la junta de aduanas, el tribunal de marcas, el tribunal de comercio y otros ${ }^{72}$.

Esta posición es secundada por varios fallos del Tribunal Constitucional y de la Corte Suprema, que puede decirse sustentan la posición dominante en ambos tribunales. Sólo a modo de ejemplo remito a los fallos del Tribunal Constitucional rol No 176 / 1993 (caso ministro de transportes y telecomunicaciones) y rol № 247/ 1996 (caso Junta General de Aduanas). De la Corte Suprema remito al fallo rol No 2536/ 2003 (caso director regional del Servicio de Impuestos Internos), cuya doctrina fue reiterada en otros fallos posteriores.

En definitiva, aunque no lo digan de un modo expreso, esta doctrina y jurisprudencia sostienen que la única función que reconoce la Constitución de 1980 es la judicial o jurisdiccional y ésta la desarrollan los tribunales de justicia. Por lo tanto, cuando el Constituyente se refiere a los órganos que ejercen jurisdicción (artículo 19 No 3 inciso 5० CPR.) se está refiriendo a los tribunales de justicia establecidos por ley (artículo 76 CPR.), sean éstos ordinarios o especiales que forman parte del poder judicial o bien

${ }^{71}$ Alguien podría intentar otra interpretación del artículo 76 CPR., señalando que tanto al Presidente de la República como al Congreso Nacional sólo les está vedado ejercer la función judicial pero no la jurisdiccional. Sin embargo, desconozco tal postura doctrinal y las consecuencias que comportaría.

${ }^{72} \mathrm{Cfr}$. Pantoja, Rolando, Justicia administrativa: ¿Tribunales ordinarios, tribunales de jurisdicción general o tribunales especiales de lo contencioso administrativo?, en La justicia administrativa, Ferrada, Juan Carlos (coordinador) (Santiago de Chile, Universidad Austral de Chile, LexisNexis, 2005), p. 105 ss. 
especiales situados fuera del poder judicial, como sería el caso, por ejemplo, del director regional del servicio de impuestos internos.

Otro sector de la doctrina nacional complementa esta concepción. Es el caso de José Luis Cea, quien sostiene que en la Constitución de 1980 el constituyente distinguió entre dos tipos de órganos y dos tipos de funciones: los tribunales de justicia que ejercen la función judicial y los órganos que ejercen la función jurisdiccional. La función judicial es desempeñada por los jueces en un proceso racional y justo mediante la sentencia respectiva y con recurso a la coacción si fuese necesario. En cambio, la función jurisdiccional puede ser desarrollada por esos jueces, pero también por otros órganos estatales e incluso privados. Por lo tanto, la función jurisdiccional puede ser desarrollada dentro o fuera de un proceso o juicio. Lo importante es que esos tribunales u órganos declaren, pronuncien o definan en casos concretos cuál es el Derecho aplicable a un asunto de su competencia, ya sea que lo hagan por medio de una sentencia, fallo, acuerdo, decreto, resolución o por otra vía. De este modo, queda claro que la función judicial envuelve siempre el ejercicio de la función jurisdiccional, pero esta última no siempre supone ejercicio de la función judicial ${ }^{73}$.

De la tesis de Cea parece concluirse que un tribunal ordinario de justicia, como por ejemplo un juzgado de letras, ejerce una función judicial como una especie de la más general función jurisdiccional. El director regional del servicio de impuestos internos o la dirección del trabajo, como órganos administrativos, pueden ejercer una función jurisdiccional no judicial. Luego el desarrollo expositivo de Cea se hace más complejo puesto que expresa que los órganos jurisdiccionales deben ser independientes e imparciales, especialmente del jefe de Estado o del gobierno ${ }^{74}$. Parece senalar entonces el autor que jueces y órganos jurisdiccionales son lo mismo. Ambos ejercen la función judicial como parte de la función jurisdiccional. Se diferenciarían entonces esos jueces u órganos jurisdiccionales de aquellos otros órganos que no son jueces ni órganos jurisdiccionales pero que ejercen jurisdicción; aquí entra la expresión "órgano que ejerce jurisdicción" a que se refiere el artículo 19 No 3 inciso $5^{\circ}$ CPR.

Entonces, tenemos que un juzgado de letras es un juez u órgano jurisdiccional y el director regional del servicio de impuestos internos es un órgano -administrativo- que ejerce jurisdicción. A ese juzgado de letras la Constitución le garantiza una independencia respecto del Presidente de la República y del Congreso Nacional. El director regional del servicio

${ }^{73}$ Cfr. Cea, José Luis, Teoría del gobierno. Derecho chileno y comparado (Santiago, Ediciones Universidad Católica de Chile, 2000), pp. 171 ss.

${ }^{74}$ Cfr. Cea, José Luis, cit. (n. 73), p. 176. 
de impuestos internos no goza de esa garantía de independencia aunque igualmente puede ejercer jurisdicción. Es que en este caso se trataría de un órgano que ejerce la función jurisdiccional.

Últimamente el Tribunal Constitucional chileno ${ }^{75}$ se ha referido ampliamente a todas estas cuestiones. Ha señalado que: "la función jurisdiccional es genérica y omnicomprensiva respecto de todos aquellos órganos que resuelven conflictos que afectan bienes y derechos de las personas, aunque no sean propiamente "tribunales" e incluso no formen parte del Poder Judicial, sin perjuicio de que en definitiva se encuentren siempre sujetos a la superintendencia disciplinaria de la Corte Suprema" (Considerando Décimo Séptimo). Luego agrega que: "[...] de suerte tal que no sólo los tribunales, propiamente tales, formen o no parte del Poder Judicial, ejercen jurisdicción sino que también lo hacen otros órganos, como algunos que incluso integran la Administración del Estado, al resolver situaciones que afecten a las personas y sus bienes. Entre dichos órganos ciertamente se encuentra el Servicio de Impuestos Internos, particularmente sus Directores Regionales, al resolver las reclamaciones tributarias, a que aluden los articulos 115 y siguientes del Código Tributario, a cuya actuación jurisdiccional también se le aplican los principios del debido proceso, como se explicará más adelante" (Considerando Décimo Octavo).

$\mathrm{Da}$ a entender en esta parte el Tribunal Constitucional que el director regional del servicio de impuestos internos no es propiamente un tribunal de justicia, sino un órgano de la administración que ejerce jurisdicción. Sin embargo, más adelante expresa que: "de este modo, en aplicación de lo dispuesto en el artículo 77 de la Carta Fundamentaly en la disposición cuarta transitoria de la misma, los tribunales que tienen atribución para conocer de las reclamaciones tributarias son los Directores Regionales del Servicio de Impuestos Internos [...]". En esta parte el tribunal cambia la denominación usada anteriormente de órgano que ejerce jurisdicción para denominarlo derechamente tribunal especial, aunque luego, más adelante en su argumentación, vuelve a denominarlo órgano que ejerce jurisdicción y no tribunal especial (Considerando Vigésimo Cuarto).

Asume luego el Tribunal Constitucional las definiciones formales de la jurisdicción dadas por la doctrina de autores como Duguit y Chiovenda, al sostener que: "lo propio de la jurisdicción es la función en que consiste y no el órgano que la ejerce" (Considerando Vigésimo Cuarto).

Esta concepción de la doctrina y jurisprudencia constitucional chilenas no es coherente con un Estado de Derecho en el cual los poderes públi-

${ }^{75}$ Vid. Sentencia del Tribunal Constitucional rol No 616-2006, de fecha 6 de septiembre de 2007. 
cos, especialmente los órganos de iniciativa política, son sometidos a un efectivo control por parte de tribunales de justicia que no reciben órdenes ni tienen vinculación con esos poderes políticos. En el apartado siguiente revisaré este aspecto.

2. Elpoder judicialy la función jurisdiccional en la Constitución de 1980. Una mirada critica bajo el contexto de la vigencia de un Estado Constitucional de Derecho.

La doctrina y jurisprudencia dominantes analizadas en el número precedente adolecen a mi modo de ver de algunos problemas que le restan sustento. Sitúan la función jurisdiccional en un universo temporal que no corresponde al de la Constitución de 1980 y desconocen las funciones de la jurisdicción asignadas constitucionalmente.

Como se decía precedentemente, la tesis de autores como Colombo recoge los planteamientos de autores como Duguit y Chiovenda que definen la jurisdicción por la función que desarrolla, función que luego Carnelutti, entre otros autores, la circunscribe a la resolución de los conflictos intersubjetivos o de la litis $^{76}$. La tesis de Carnelutti es coherente con un modelo de Estado que asume un rol pasivo consistente en ser un mero árbitro de las disputas que se dan entre los ciudadanos ${ }^{77}$. El Estado y la jurisdicción, como parte de éste, son mero cauce de pacificación social.

El problema de la concepción de la función judicial de Carnelutti que, como hemos visto, sigue un sector de nuestra doctrina, es que deja fuera del horizonte los fines principales de la jurisdicción. Como lo hace ver un sector de la doctrina procesal más contemporánea ${ }^{78}$, la concepción de la función jurisdiccional como solución de controversias excluye la idea que el proceso pueda servir para garantizar y asegurar la legalidad en general a través de la efectiva y puntual actuación de los derechos de los particulares. Por otra parte, Carnelutti parece situar la función jurisdiccional en un contexto donde el Derecho se aplica a situaciones en que los ciudadanos tienen intereses contrapuestos, dejando de lado la evolución de la función jurisdiccional para resolver los conflictos entre los órganos del Estado y los ciudadanos y entre los propios órganos del Estado, cuestiones propias de una justicia administrativa y de otra de carácter constitucional. En este

${ }^{76}$ Cfr. Carnelutti, Francesco, cit. (n.38), p. 62

${ }^{77}$ Vid. Damaska, Mirjan, I volti della giustizia e del potere. Analisi comparatistica del processo (Bolonia, Il Mulino, 1991), pp. 136 ss.

${ }^{78}$ Por todos vid. TARUfFo, Michele, La justicia civil: ¿opción residual o alternativa posible?, en Andrés IbáŃEz, Perfecto (editor), Corrupción y Estado de Derecho. El papel de la Jurisdicción (Madrid, Trotta,1996), p. 138. 
sentido se omite la función de control que asumen los jueces en un Estado de Derecho contemporáneo.

La función jurisdiccional de control es exigida por nuestra Constitución respecto de la Administración del Estado (artículo 38 inciso $2^{\circ} \mathrm{CPR}$. y artículo $93 \mathrm{No}^{\circ}$, No 4o, No $8^{\circ}$, No $9^{\circ}$, No 13 y No $16^{\circ}$ CPR.) y del

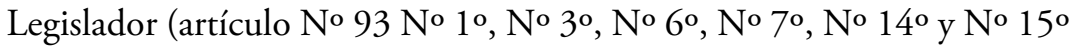
CPR.). El poder judicial ordinario a través del Recurso de Protección (artículo 20 CPR.) también puede cumplir esa función de control cuando los poderes del Estado vulneran los derechos fundamentales de los ciudadanos. Con un carácter más específico el habeas corpus (artículo $21 \mathrm{CPR}$.) también permite a los jueces controlar los actos del Estado.

De conformidad con lo dicho, se puede aseverar que la concepción de la función jurisdiccional asumida mayoritariamente en Chile que pone énfasis en la eliminación del conflicto surgido entre individuos parece no atribuirle mucha importancia a la independencia judicial. Mientras ese juez que pertenece al Estado no esté del lado de uno de esos sujetos privados de la contienda se satisfará un mínimo de imparcialidad, con prescindencia de si ese juez pertenece al poder judicial, al legislativo o al ejecutivo. Por el contrario, en una concepción de la función jurisdiccional como contra-poder, la independencia judicial adquiere mucha relevancia. Es precisamente esa independencia la que permitirá que la decisión de los jueces no sea influenciada por los otros poderes constitucionales. Sólo así puede existir un poder del Estado que funcione como control sobre la actividad de los otros poderes. Sólo así se garantiza la legalidad de todo el sistema jurídico ${ }^{79}$.

Una concepción más contemporánea de la función jurisdiccional que esté por lo demás conforme con las exigencias constitucionales, viene a significar que las características estructurales de los órganos judiciales no son nada irrelevantes para el ejercicio de la función jurisdiccional, al contrario de lo que sostenía Duguit en Francia, Chiovenda en Italia y un sector importante de la doctrina en nuestro país. La independencia del órgano judicial es especialmente importante cuando la imparcialidad puede hacerse problemática en ciertos casos, como cuando el tercero que debe juzgar es un órgano que pertenece a la administración pública. Este es el típico caso que justifica la necesidad de la independencia para el desarrollo de la función jurisdiccional ${ }^{80}$.

La estructura del órgano, entonces, sí es relevante para definir la función

${ }^{79}$ Vid. Rentería, Adrián. Discrecionalidad judicial y responsabilidad (2ª edición, México D.F., Fontamara, 2002), p. 209.

${ }^{80}$ Vid. Guarnieri, Carlo, cit. (n. 18), p. 37. 
jurisdiccional. De lo contrario no habría cómo asegurar la libertad y los derechos de las personas frente al poder abusivo de los poderes políticos del Estado.

En este mismo orden de ideas, si la independencia de los tribunales de justicia u órganos que ejercen jurisdicción no fuese relevante para definir la función jurisdiccional, no se pueden entender correctamente algunos preceptos de la Constitución chilena, como es el caso del artículo 38 inciso $2^{\circ} \mathrm{CPR}$. Pongamos un ejemplo. Supongamos que el servicio de impuestos internos liquida un impuesto aplicando ilegalmente la normativa tributaria. Esa ilegalidad del órgano administrativo afecta el derecho de propiedad de un contribuyente. A ese contribuyente el artículo 38 inciso $2^{\circ} \mathrm{CPR}$. le asegura que podrá reclamar del acto ilegal ante el tribunal que determine la ley. El tribunal que determina la ley, según el Código Tributario vigente (artículo 115), es el director regional del servicio de impuestos internos, órgano que como sabemos pertenece a la administración del Estado. ¿¿Se cumple con la función de control y garantía que asegura el referido precepto constitucional? Es evidente que no. En este caso es la administración del Estado quien controla la legalidad de la actuación de un órgano que también forma parte de la administración del Estado. No hay ahí función de control alguna. No hay tampoco garantía para ese contribuyente en la tutela de sus derechos y desde luego se vulnera el fin del artículo 38 inciso $2^{\circ} \mathrm{CPR}$.

Hay que señalar que cuando se analiza la jurisdicción como función, se pretende identificar dentro de las funciones estatales una concreta que se encomienda en régimen de monopolio a unos órganos dotados de determinadas características, las que estarán preordenadas a garantizar que la función se desarrollará según ciertas exigencias que se consideran de capital importancia en el Estado de Derecho. Por ello, en las democracias contemporáneas la función jurisdiccional se encomienda en régimen de monopolio a jueces independientes e imparciales y se prohíbe que pueda ser ejercida por órganos que no tienen tales notas ${ }^{81}$.

La organización de los poderes públicos en la democracia chilena debe ser entendida bajo estas coordenadas. Por ello, debe entenderse que en la Constitución de 1980 la función jurisdiccional la desarrollan con absoluta exclusividad los tribunales de justicia establecidos por ley, tribunales que se definen por sus notas de independencia respecto del ejecutivo y del legislativo para que sólo así puedan aplicar imparcialmente los preceptos jurídicos que estos poderes políticos crean. Esos tribunales podrán pertenecer o no a la estructura burocrática denominada poder judicial. Ello es

${ }^{81}$ Vid. De Oтто, Ignacio, Estudios sobre el Poder Judicial (Madrid, Ministerio de Justicia, Secretaría General Técnica, Centro de Publicaciones, 1989), p. 17. 
irrelevante. Lo único que importa si se quiere tener y preservar un Estado de Derecho, es que esos tribunales sean independientes en los términos ya apuntados.

De este modo, cuando la Constitución chilena en su artículo 19 No 3 se refiere a los órganos que ejercen jurisdicción, debe entenderse dicha expresión como sinónima de tribunales de justicia independientes. Ante dichos órganos o tribunales, exige el referido precepto constitucional, debe desarrollarse un procedimiento tal que pueda entenderse que cumple con las garantías de racionalidad y justicia, es decir, las garantías de un debido proceso.

Ahora bien, si tal exigencia de un debido proceso puede ser aplicada a otros órganos distintos a los tribunales de justicia u órganos que ejerzan jurisdicción, como por ejemplo a aquellos que forman parte de la administración de Estado, ello es un asunto que escapa de este análisis. Sea como fuere esa respuesta, ello no debe trastocar la organización de los poderes públicos chilenos. Y en lo que interesa a efectos de este trabajo, no debe permitir que la actividad jurisdiccional sea desarrollada por órganos que carezcan de independencia de los poderes con iniciativa política. He aquí lo esencial.

\section{CONCLUSIONES}

Entendiendo que la República de Chile es una democracia representativa organizada como Estado de Derecho, se puede aseverar que la Constitución Politica de Chile vigente reconoce una sola función en materia de justicia: la función jurisdiccional, que el artículo 76 CPR. denomina judicial, la que es exclusiva de los tribunales de justicia establecidos por la ley. Por las tareas que en dicha Constitución se les reconoce a los tribunales de justicia, en especial el control de legalidad de los actos de la administración y del legislativo, así como la tutela de los derechos fundamentales, esa función sólo puede ser desarrollada por tribunales de justicia que imparcialmente apliquen la legalidad vigente. Por ello deben ser independientes de los poderes de representación política. Sin independencia no hay órgano ni función jurisdiccional. Y sin independencia no hay posibilidad de actividad imparcial.

En este sentido, no puede entenderse que órganos que pertenecen o tienen vinculación con los poderes ejecutivo o legislativo desarrollen tal función jurisdiccional. El caso más típico es el de la actividad juzgadora de la administración del Estado, como ocurre con el director regional del servicio de impuestos internos. Se trata de actividad administrativa la que jamás podrá ser considerada una actividad jurisdiccional.

[Recibido el 4 de marzo y aceptado el 5 de mayo de 2008]. 


\section{BIBLIOGRAFÍA}

ACKerman, Bruce, La nuova separazione dei poteri. Presidenzialismo e sistemi democratici (Roma, Carocci, 2003).

Aldunate, Eduardo, La independencia judicial. Aproximación teórica, consagración constitucional y crítica, en Revista de Derecho Universidad Católica de Valparaíso 16 (1995).

Andrés Ibáñez, Perfecto, Poder judicial y juez en el Estado constitucional de Derecho. El sistema del Consejo en La experiencia jurisdiccional: Del Estado legislativo de Derecho al Estado constitucional de Derecho (Madrid, Consejo General del Poder Judicial, 1999).

Atria, Fernando, Inaplicabilidad y coherencia: contra la ideología del legalismo, en Revista de Derecho Universidad Austral de Chile 12 (agosto 2001), número especial: "Justicia Constitucional".

Atria, Fernando, La improbabilidad de la jurisdicción, en La judicatura como organización (Santiago de Chile, Expansiva - Instituto de Estudios Judiciales, 2007).

Balboni, Enzo, Potere politico e funzione giurisdizionale: Il fondamento costituzionale, en La riforma dell'ordinamento giudiziario tra indipendenza della magistratura e primato della politica (Milano, Giuffrè, 2006).

Bluntschli, Juan Gaspar, Derecho público universal, parte primera, teoría general del Estado (Madrid, F. Góngora y Compañía Editores, 1880).

Bordalí, Andrés, La Administración Pública ante los tribunales de justicia chilenos, en Revista Chilena de Derecho 33 (2006) 1.

Carnelutti, Francesco, Derecho y proceso (Buenos Aires, Ediciones jurídicas Europa -América, 1971).

Cea, José Luis, Teoría del gobierno. Derecho chileno y comparado (Santiago, Ediciones Universidad Católica de Chile, 2000).

Chiovenda, José, Principios de Derecho Procesal Civil (Madrid, Reus, 1977), I.

Colombo, Juan, La competencia ( $2^{\text {a }}$ edición, Santiago, Editorial Jurídica de Chile, 2004).

Damaska, Mirjan, I volti della giustizia e del potere. Analisi comparatistica del processo (Bolonia, Il Mulino, 1991).

De Отто, Ignacio, Estudios sobre el Poder Judicial (Madrid, Ministerio de Justicia, Secretaría General Técnica, Centro de Publicaciones, 1989).

Duguit, Leon, Manual de Derecho Constitucional (Granada, Comares, 2005).

Fioravanti, Maurizio, Estado y Constitución, en Fioravanti, Maurizio (coordinador), El Estado moderno en Europa. Instituciones y Derecho (traducción castellana de M. Martínez Neira, Madrid, Trotta, 2004).

Giacobbe, Giovanni, Autonomia della Magistratura, indipendenza del giudice, poteri del Ministro di Grazia e Giustizia en L'indipendenza della giustizia, oggi (Milano, Giuffrè, 1999).

Guarnieri, Carlo, L'indipendenza della magistratura (Padova, Cedam, 1981).

Kelsen, Hans, Giurisdizione e amministrazione, en Geraci, Carmelo (editor), Il primato del parlamento (Milano, Giuffrè, 2002).

LAFERRIÈre, Édourd, Traité de la jurisdiction administrative et de recours contentieux (edición facsimilar del original de 1887, París, LGDJ, 1989) I.

LASTARria, José Victorino, Estudios politicos i constitucionales (Santiago, Imprenta, Litografía i Encuadernación Barcelona, 1906), I. 
Loewenstein, Karl, Teoría de la Constitución (2a edición, Barcelona, Ariel, 1976).

Long, Marceau et al, Les grands arrêst de la jurisprudence administrative (15a edición, París, Dalloz, 2005).

Montesquieu, El espiritu de las leyes (Madrid, Biblioteca Auxiliar del Jurisconsulto y Publicista, 1845).

Mortara, Lodovico, Lo Stato moderno e la giustizia (Napoli, Edizioni Scientifiche Italiane, 1992).

Navarro, Enrique, La teoría general de la división de poderes en la Constitución de 1980 en Revista de Derecho Universidad Católica de Valparaíso 14 (1991-1992).

Ordóñez, David, Jueces, derecho y politica. Los poderes del juez en una sociedad democrática (Navarra, Thomson Aranzadi, 2004).

Pantoja, Rolando, Justicia administrativa: ¿Tribunales ordinarios, tribunales de jurisdicción general o tribunales especiales de lo contencioso administrativo?, en La justicia administrativa, Ferrada, Juan Carlos (coordinador) (Santiago de Chile, Universidad Austral de Chile, LexisNexis, 2005).

Pedraz, Ernesto, Constitución, jurisdicción y proceso (Madrid, Akal, 1990).

Pizzorusso, Alessandro, L'organizzazione della giustizia in Italia. La magistratura nel sistema politico e istituzionale (Torino, Einaudi, 1990).

Rebuffa, Giorgio, La funzione giudiziaria (3a edición, Torino, 1993).

Rentería, Adrián. Discrecionalidad judicial y responsabilidad (2a edición, México D.F., Fontamara, 2002).

SCHedler, Andreas, Argumentos y observaciones: De criticas internas y externas a la imparcialidad judicial, en Isonomía 22 (abril de 2005).

Schmitt, Carl, Teoría de la Constitución (Madrid, Alianza Editorial, 1992).

Spadaro, Antonino, Il fenomeno della pubblicizzazione degli interessi privati e di riflesso, della privatizzazione degli interessi pubblici: Una piccola contribuzione sulla crisi dell' etica pubblica costituzionale en Diritto e potere nell Italia di oggi (Torino, Giappichelli, 2004).

TARUfFo, Michele, La justicia civil: ¿opción residual o alternativa posible?, en ANDrÉs IвÁŃEZ, Perfecto (editor), Corrupción y Estado de Derecho. El papel de la Jurisdicción (Madrid, Trotta,1996).

Troper, Michel, La separazione dei poteri e la storia costituzionale francese (Napoli, Edizioni Scientifiche Italiane, 2005).

Verdugo, Mario - Pfeffer, Emilio - Nogueira, Humberto, Derecho Constitucional (Santiago, Editorial Jurídica de Chile, 1994), I. 
